\title{
Epistemology of Disagreement: The Good News
}

\author{
David Christensen \\ University of Vermont
}

We all live out our lives in states of epistemic imperfection. Most obviously, this is true because the evidence on which we base our beliefs is limited. Only a little less obviously, we live in states of epistemic imperfection because we do not always respond to the evidence we have in the best way. Given that our epistemic condition consists in imperfect responses to incomplete evidence, part of being rational involves taking account of these sources of imperfection.

Fortunately, each of us is confronted every day by opportunities for epistemic self-improvement. Most frequently, opportunity arrives in the form of evidence that bears directly on the subject matters of our beliefs: hearing the evening weather report, I can revise upward my confidence that it will rain tomorrow. Other opportunities for epistemic self-improvement address, not our deficits in evidence, but our deficits in responding to the evidence: reading a study showing that professors vastly overrate their teaching abilities, I can revise downward (at least temporarily $)^{1}$ my confidence that I'm a dynamite teacher.

One fairly common situation that may present opportunities for improvement is that of discovering that another person's belief on a given

This essay was read in fall 2004 at Princeton University, and I'd like to thank the audience at that talk for stimulating discussion. I'd also like to thank the following people for helpful discussions of this material or comments on earlier drafts: David Barnett, Sin yee Chan, Adam Elga, Rich Feldman, Tom Kelly, Hilary Kornblith, Arthur Kuflik, Don Loeb, Bill Mann, Mark Moyer, Derk Pereboom, Jim Pryor, Jonathan Vogel, Adam Wager, and three anonymous referees for the Philosophical Review.

1. See Elga 2005. 
topic differs markedly from one's own. And it is this sort of opportunity that I want to concentrate on here. How should I react when I discover that my friend and I have very different beliefs on some topic? Thinking about belief in a quantitative or graded way, the question concerns cases in which my friend and I have very different degrees of confidence in some proposition P. Should my discovery of her differing degree of belief in $\mathrm{P}$ lead me to revise my own confidence in $\mathrm{P}$ ? $^{2}$

In some cases, the answer is easy. Suppose, for example, that my friend gives moderate credence to the proposition that I had cereal for breakfast, while I, with my vivid memory of enjoying bacon and eggs, am virtually certain that it's false. Here, the disparity between our beliefs is most reasonably explained by her lacking evidence that I have. Similarly, suppose my friend thinks it highly likely that her child is the best violinist in his school, and she can't understand why he hasn't been made first chair. I, who have also heard the child play numerous times, put quite a lower probability on his being best in his school. Again, the obvious explanation for the discrepancy in our beliefs is that it's my friend's problem; this time, it happens to be a problem in how she has responded doxastically to the ample evidence we both have. In both cases, there seems to be little or no reason for me to revise my belief after learning of hers. Other cases resolve themselves, equally obviously, in the opposite direction. If I have reason to believe that my friend has more evidence, or is likely to be better at responding to the evidence, I should change my belief upon learning of hers.

But some cases are more interesting. In particular, there are cases where one does not have any special reason to think that the person with whom one disagrees has more (or less) evidence, or is more (or less) likely to react to that evidence in the right way. Suppose I find out that my friend disagrees with me about P: she has moderately high confidence that it's true, and I have moderately high confidence that it's false. But to the best of my knowledge, my friend is just as well informed as I am-in fact, we may suppose that my friend and I have had long discussions in which we share every bit of evidence we can think of that's relevant to P. And suppose further that I have good reason to believe that my friend and I are equally intelligent and rational, and that I know of no general

2. Much of the discussion of this issue in the literature is in terms of an all-or-nothing model of belief, rather than the graded model I'll concentrate on. I want to focus first on degrees of belief because I want to look carefully at the rational effects of evidence, and evidence may change degrees of belief even when it doesn't change all-or-nothing beliefs. I will, however, examine the issue in terms of all-or-nothing beliefs below. 
reason (like the fact that people tend to be biased toward their children) to think either of us is especially likely to be particularly good, or bad, at reacting to evidence on this particular topic - no reason, that is, aside from the fact that my friend disagrees with me about P. In other words, my friend seems to be what some have called an "epistemic peer." In this sort of case, should I revise my belief?

Some have worried that if I cannot hold onto my beliefs in the face of disagreement by apparent epistemic peers, I'll be forced into an unacceptable degree of skepticism about controversial areas, such as philosophy, politics, and morality. Peter van Inwagen $(1996,275)$ puts the problem, as it applies to philosophical beliefs, as follows (here by "philosophical skeptics" van Inwagen means "people who can't see their way clear to being nominalists or realists, dualists or monists, .. . people who have listened to many philosophical debates but have never declared a winner"):

I think that any philosopher who does not wish to be a philosophical skeptic-I know of no philosopher who is a philosophical skepticmust agree with me that ... it must be possible for one to be justified in accepting a philosophical thesis when there are philosophers who, by all objective and external criteria, are at least equally well qualified to pronounce on that thesis and who reject it.

Van Inwagen extends his point to politics and to his ultimate target, religious belief. Others have expressed similar worries. ${ }^{3}$

I will argue that in a great many cases of the sort van Inwagen and others seem to have in mind, I should change my degree of confidence significantly toward that of my friend (and, similarly, she should change hers toward mine). I will first examine an initially attractive way of denying that the disagreement of peers should typically occasion belief revision. I'll then consider some simple, somewhat idealized cases that motivate a general demand for revision, develop and defend an account of when and why belief revisions are called for, examine the effect of relaxing the idealizations involved in the central cases, and finally explore the extent to which the position I defend entails an objectionable degree of skepticism.

3. See Plantinga 2000, chap. 13 for a somewhat similar argument concentrating on moral examples. Thomas Kelly (2005) and Richard Feldman (n.d.) also see a threat of skepticism as flowing from the claim that disagreement by peers should occasion changing one's beliefs. 


\section{Why Not Live and Let Live?}

One reason for doubting that the disagreement of peers should typically occasion belief revision flows from a permissive conception of rational belief. ${ }^{4}$ It seems plausible, at least at first, that there could be more than one completely reasonable epistemic response to a given evidential situation. Perhaps, two people could share all relevant evidence, react to that evidence faultlessly, and yet reach different conclusions. If that is possible, then it might seem that in the case of disagreement with a peer, one could adopt what Adam Elga once called (in correspondence) a "live-and-let-live" attitude. The live-and-let-live attitude seems, at least at first, appealingly open-minded. One might think, "She has her belief, and I have mine. Our evidence is the same, but for all I know we're both perfectly rational in our reactions to this evidence." To refuse to adopt this attitude might seem to betray an insufficient appreciation of epistemic diversity. ${ }^{5}$

But it seems to me that the "live-and-let-live" attitude is hard to maintain-or, at least, that it should be. To see why, let us focus on a specific case. Suppose that my friend and I are doctors in the same practice. One of my patients is in very serious condition, and my friend and I both examine him, study his medical records, read the relevant literature-and come to conflicting conclusions. There are, it turns out, just two theories that might explain his symptoms. Theory A is somewhat simpler, but theory B fits a bit better with the data. My friend has about 65 percent credence in $\mathrm{B}$ and 35 percent in $\mathrm{A}$, while for me, the two figures are reversed. When my friend and I talk the case over as thoroughly as two intelligent people can ever discuss anything, we come to see that she is more moved by the fit with reported data, whereas I'm more moved by simplicity. I take it that this is at least one sort of case-somewhat different weightings of fully reasonable epistemic desiderata-that make plausible the idea that rationality is not so restrictive as to single out one rational response to each evidential situation. How should I react to my friend's belief in this case?

4. This sort of conception is defended in Rosen 2001.

5. Richard Feldman (forthcoming and n.d.) considers, and rejects, this way of defusing disagreements, for reasons similar to those offered below. My term "Rational Uniqueness," referring to the assumption that there is a unique maximally rational response to a given evidential situation, is intended to echo Feldman's "Uniqueness Thesis," which is essentially the same idea applied to all-or-nothing (as opposed to graded) beliefs. 
It seems to me that there's considerable pressure for me to do at least one of two things: (1) to think that my friend has not given the right relative weights to simplicity and fit with data, and hence that she has not responded to the evidence maximally rationally, or (2) to move my belief in the direction of hers. There's something unstable about holding onto my belief while acknowledging that a different belief enjoys equal support from the evidence. ${ }^{6}$

This seems particularly clear if important things hang on the belief in question. Suppose that theories A and B would mandate different and mutually incompatible medical treatments. If $\mathrm{A}$ is true, one treatment is vastly more likely to save the patient's life, whereas if B is true, the other treatment is much more likely to succeed. We might even suppose that I discover the treatment mandated by theory A (the one I favor) to involve excruciating pain. Given that the patient's life is at stake, if the A-mandated treatment has a significantly greater chance of saving him (as it does if we take theory A to be 65 percent likely to be true), there's no question that it's what I should prescribe. But it seems wrong for me to say to my friend, "Well, I admit that you have considered all the same evidence as I have, and I admit that your putting the probability of theory A at only 35 percent enjoys just as much rational support from our evidence as does my putting the probability at 65 percent. But I've come to come to the latter opinion, so I'm recommending the excruciatingly painful procedure."

Here's another way to think about the question: do I think that her weighting leads in general to equally accurate beliefs? If so, then why think my belief is likely to be more accurate now? I could, of course, be lucky. But it would seem clearly wrong for me to put my patient through excruciating pain on the assumption that I lucked out. On the other hand, if I think her weighting does not lead in general to equally accurate beliefs, why should I grant that it's just as rational to form beliefs using that weighting?

6. A point along similar lines is made by Roger White (2005). See White's paper for a more thorough criticism of permissive notions of epistemic rationality.

7. I should note that to say that I believe my weighting policy is more rational than hers need not commit me to being able to give an ultimately non-question-begging defense of my policy. Hume, I think, showed us that this cannot be the standard for rational belief-forming policies. But to the extent that I regard it as my duty to prescribe the painful treatment, I must regard my colleague in somewhat the way I regard the counterinductivist: she's not completely rational even if I can't demonstrate that. We should not take the impossibility of non-question-beggingly demonstrating that one 
And so it seems to me doubtful that one can invoke a permissive notion of rationality to dismiss the significance of the opinions of otherwise rational people with whom one disagrees. Interestingly, the "live-and-let-live" attitude, despite its initial open-minded flavor, ends up allowing an implausibly closed-minded attitude toward the beliefs of others. So let us proceed for the present on the assumption that there is only one maximally rational response to a given evidential situation. I will, however, explore the effects of relaxing this assumption below. ${ }^{8}$

\section{Some Simple Cases}

Let us begin by considering some cases of disagreement in which it's as clear as possible that my friend and I have the same evidence and that we're, in general, equally good at responding to that sort of evidence. I take these to be cases where my friend, to use van Inwagen's terms, "by

method of forming beliefs is uniquely rational to show that more than one method of forming beliefs is rationally acceptable. (Compare Feldman forthcoming, III B, which may reject my view here.)

8. It might seem that once one thinks in degree-of-belief terms, the alternative to a permissive notion of rational belief is obviously untenable. Many have noted that in situations in which the evidence bearing on some proposition $\mathrm{P}$ is relatively meager, it does not seem that one unique number could possibly be singled out as the uniquely rational degree of belief in $\mathrm{P}$. But rejecting permissive conceptions of rationality need not commit one to representing the rational response to every evidential situation with a single probability function. Most favor using sets of such functions (see Kaplan 1996, 23ff. for a version of this view and references to others). On this sort of view, one can hold that the uniquely rational response to an evidential situation is representable by a particular set of probability assignments, and the uniquely rational attitude toward proposition $\mathrm{P}$ is represented by a particular range of values between 0 and 1 .

Another reason that might be given for adopting a permissive conception of rationality is that rationality is likely to be a vague concept. So there won't be one response that the evidence precisely mandates. But vagueness does not entail permissiveness. Suppose that it's vague whether a 0.57 degree of belief in $\mathrm{P}$ is rational (or, thinking in terms of the type of model described in the previous note, suppose it's vague whether 0.57 is assigned to $\mathrm{P}$ by a member of the rational set of probability functions). Obviously, that does not entail that one is rationally permitted to have a 0.57 degree of belief in $\mathrm{P}$ (or have a belief state described by a set of probability functions one of which assigns 0.57 to $\mathrm{P}$ ). And if it's vague whether your belief or my belief is rationally preferable, that does not show that our beliefs are rationally on a par. Thus there's no straight road from the vagueness of the boundaries of rational belief to a permissive account of rationality.

For a somewhat related discussion of vagueness, see Feldman n.d. Feldman argues that vagueness in the relation between evidence and all-or-nothing belief would not allow full disagreement cases (where I believe $\mathrm{P}$ and my friend believes not-P). 
all objective and external criteria [is] at least equally well-qualified" to pronounce on the relevant issue:

Suppose that five of us go out to dinner. It's time to pay the check, so the question we're interested in is how much we each owe. We can all see the bill total clearly, we all agree to give a 20 percent tip, and we further agree to split the whole cost evenly, not worrying over who asked for imported water, or skipped desert, or drank more of the wine. I do the math in my head and become highly confident that our shares are $\$ 43$ each. Meanwhile, my friend does the math in her head and becomes highly confident that our shares are $\$ 45$ each. How should I react, upon learning of her belief?

I think that if we set the case up right, the answer is obvious. Let us suppose that my friend and I have a long history of eating out together and dividing the check in our heads, and that we've been equally successful in our arithmetic efforts: the vast majority of times, we agree; but when we disagree, she's right as often as I am. So for the sort of epistemic endeavor under consideration, we are clearly peers. Suppose further that there is no special reason to think one of us particularly dull or sharp this evening-neither is especially tired or energetic, and neither has had significantly more wine or coffee. And suppose that I didn't feel more or less confident than usual in this particular calculation, and my friend reports that she didn't either. If we set up the case in this way, it seems quite clear that I should lower my confidence that my share is $\$ 43$ and raise my confidence that it's $\$ 45$. In fact, I think (though this is perhaps less obvious) that I should now accord these two hypotheses roughly equal credence.

The restaurant case is designed to be simple in two ways: in the evidential situation and in the evaluation of the general capacities my friend and I exercise in reacting to that sort of evidential situation. This makes our intuitions about the case particularly clear. But the same lessons emerge, I think, from cases involving a bit more complexity. Let us consider a case that more closely resembles more interesting cases of disagreement.

Suppose I'm a meteorologist who has access to current weather data provided by National Oceanic and Atmospheric Administration, the National Weather Service, and so forth, and that I have learned to apply various models to use this data in making predictions. To make this less like the restaurant case and more like many cases of real-life disagreement, let us suppose that applying the models is not just a matter of clear-cut calculation-say it involves similarity judgments. After 
thoroughly studying the data and applying the various models I know, I come to have a 55 percent level of credence in rain tomorrow. But then I learn that my classmate from meteorology school-who has thoroughly studied the same data, knows the same models, and so on-has arrived at only a 45 percent level of credence. We may even suppose that we have accumulated extensive track records of past predictions, and she and I have done equally well. (We might have been scored by Brier score ${ }^{9}$ on our probabilistic forecasts, or asked to answer yes/no questions, and scored for percentage correct.) Should I take her opinion into account and reduce my confidence in rain?

It seems obvious to me that, absent some special reason for thinking that I had some advantage over her in making this forecast, I should revise my belief. ${ }^{10}$ Even when the evidence does not entail the answer to the relevant question, disagreement of an epistemic peer provides reason for belief revision. From my point of view, this is a good thing: other people's opinions, in these circumstances, present opportunities for epistemic improvement. But others would reject this verdict. In the next few sections, then, I'll examine some of their objections, with an eye toward developing and defending an account of how and when the disagreement of epistemic peers should occasion belief revision.

\section{Explaining Disagreements and Adjusting Beliefs}

The intuition supporting belief revision in the meteorology case depends on my acknowledging that my friend is as likely as I am to react correctly to the data we have. But it might be objected that even if I have ample reason to think my friend is in general as good as I am at predicting the weather, in this particular case, I have some special evidence that she's made a mistake. After all, I believe that the data support a 55 percent credence in rain, and her credence in rain is only 45 percent. My general reason for trusting my friend is defeated in this case by her reaching what, to my mind, is the wrong conclusion.

Richard Foley (2001) expresses thoughts along roughly these lines, at least in cases where one does not have much information about the person with whom one disagrees. Foley's general position is that my indis-

9. The Brier score is a standard way of measuring accuracy of probabilistic forecasts. It averages the squared differences between the forecaster's announced probabilities for propositions and the propositions' truth values (where 1 is true and 0 is false).

10. Feldman (forthcoming and n.d.) draws similar morals (in terms of all-or-nothing belief) from similar cases. 
pensable trust in my own cognitive faculties, combined with the similarity between my faculties and the faculties of others, grounds a presumption in favor of believing as others do. But this presumption is defeasible by information that the other person has a history of errors, lacks important evidence, is poorly trained, or is cognitively impaired. And, in addition, Foley (ibid., 108) writes:

there is an important and common way in which the prima facie credibility of someone else's opinion can be defeated even when I have no specific knowledge of the individual's track record, capacities, training, evidence or background. It is defeated when our opinions conflict, because, by my lights, the person has become unreliable.

Foley (ibid., 110) says that I might still have reason to defer to the other person's opinion, "but only if I have special reasons indicating that he or she is better positioned than I to assess the claim in question." 11 Applied to the case of degrees of belief rather than beliefs taken in an all-or-nothing way, he (ibid., 114) writes the following about the case where the other person's degree of belief in $\mathrm{P}$ conflicts with mine:

the prima facie reason I have to trust your opinion is defeated, and hence I have no reason to move my opinion in the direction of your opinion unless I have special reasons for thinking that you are in an especially good position to assess $\mathrm{P}^{12}$

Thomas Kelly (2005) develops in greater detail a somewhat similar argument for the legitimacy of sticking with one's original belief in cases of conflict. He (ibid., 179) specifically addresses cases like the weather-forecasting case, where I reasonably believe that there is an ini-

11. Foley's position (at least with respect to all-or-nothing belief) is more nuanced than this passage may suggest. He says that one shouldn't "defer" (that is, adopt the other person's belief) unless one has reason to think the other person better positioned. But if one has special reason to think the other person is equally well positioned (as would be the case in an all-or-nothing belief version of our weather-forecasting case), he thinks one should suspend belief. Lacking special information about the other person, however, one should not even suspend. I will discuss cases in which one lacks such special information below. For the present, I want just to focus on the basic idea that disagreement by itself serves to undermine the evidential import of another's beliefs.

12. Note that Foley here seems to reject any change in degree of belief unless I have reason to believe that my friend is actually better positioned. This seems to go against the spirit of advocating suspension of all-or-nothing belief when I have special reason to think my friend equally well placed. Since Foley concentrates mainly on all-or-nothing belief, this last quoted passage may not represent his considered view. 
tial symmetry in both evidence and ability to react to evidence between my friend and me:

Suppose that, as it turns out, you and I disagree. From my perspective, of course, this means that you have misjudged the probative force of the evidence. The question then is this: why shouldn't I take this difference between us as a relevant difference, one which blocks the otherwise perfect symmetry?

It seems to me that there is clearly something right about this line. As applied to the weather case, my discovering that my friend has reached what seems to me to be the wrong conclusion does constitute evidence that she has made a mistake, and thus does give me reason to trust her opinion less than I ordinarily would. However, another point needs equal emphasis: the fact that she disagrees with my prediction also constitutes evidence that $I$ have made a mistake. ${ }^{13}$ So it's not clear so far that any asymmetry has developed.

To focus in on the symmetry question, let me begin with an admittedly crude analogy: I look at my watch, a one-year-old Acme that has worked fine so far, and see that it says 4:10. Simultaneously, however, my friend consults her watch-also a one-year-old Acme with a fine track record-and it reads 4:20. When she tells me this, it clearly gives me new evidence that her watch is fast: I should not trust her watch as much as I would have before finding out that it disagreed with mine. But just as clearly, I've just gotten new evidence that my watch is slow, and this should diminish my trust in it. In this case, it's obvious that the fact that one of the watches is on my wrist does not introduce an epistemically relevant asymmetry.

But perhaps the watch example misleads by introducing a thirdperson perspective into the picture: my watch's mechanism is not part of me. Kelly cites Foley's claim that "it is deeply misleading to think about [conflicts of opinion] in terms of a model of neutral arbitration between conflicting parties" (Foley 2001, 79). And it is certainly true that when I consider how to regard my friend's disagreement, I must do so from within the first-person perspective-that is, using my own beliefs. Might this give my beliefs-which include my belief about the matter on which my friend and I disagree-a kind of privileged position that the watch on my wrist doesn't share? Let us consider, then, whether taking a first-

13. This point is also noted in Trakakis n.d. 
person perspective on this sort of situation provides an asymmetry that is epistemically relevant in assessing evidence of error.

It seems to me that there is considerable support for symmetry even from within a first-person point of view. Consider how the weatherforecasting example might unfold over time. Before we come up with our forecasts, my friend and I know that our skills, education, and track records are equally good and that we'll be spending the same time studying the same data. Suppose we consider in advance the question of who will be more likely to have made a mistake if we end up disagreeing. We might even wonder who will be more likely to have made a mistake if she ends up putting the probability of rain at 45 percent and I put it at 55 percent. I take it as obvious that each of us-from within his or her own, first-person, perspective-should say, in advance, that we're equally likely to make an error in such a case. And now suppose we do our analyses, we each feel confident in our reasoning, we announce the results, and find out that we have, indeed, come up with different predictions: she has actually come up with 45 percent and I with 55 percent.

At this point, has an asymmetry developed that would be relevant to the question of who was more likely to have made a mistake? True, I may now have in mind, or directly feel the force of, the reasoning supporting my answer, and not the reasoning supporting hers. But can this development suddenly license me in thinking that her reasoning is more likely to be mistaken than mine? It seems to me that it cannot. After all, when I said, before we did our analyses, that we'd be equally likely to have made a mistake in the case of conflict, I knew that in such a case I'd have in mind some apparently convincing reasoning behind my answer. Now I do have such reasoning in mind, as does my friend, of course. But I cannot see how this would provide me with any justification to think now that my reasoning is less likely to be mistaken. ${ }^{14}$

Thus it seems to me that taking a first-person perspective on the situation does not license me in thinking that disagreement with my friend is better explained by her error than by mine.

14. Of course, it could be that during the time of coming up with the prediction, I get some new evidence bearing on the question of who's more likely to make a mistake: I may feel unusually sleepy and distracted, or especially crisp and alert, or I may see my friend yawning, or concentrating intensely. But this would just be like the case of conflict with someone antecedently known not to be an epistemic peer. The question at issue here is whether I, having come up with 55 percent, should take the mere fact that my friend now puts the probability of rain at 45 percent as evidence that she is more likely than I to have made an error. 
Given that my friend and I are generally reliable thinkers who have studied the same evidence, the fact that we disagree will be explained by the fact that at least one of us has made a mistake in this case. But intuitively, the explanation in terms of my friend's mistake is no more reasonable than the explanation in terms of my mistake. And I should acknowledge this by moving my belief toward hers.

Of course, putting the issue in terms of assessing explanations for the disagreement does not, all by itself, provide an illuminating account of the force of disagreement. For it raises the question: what are the conditions under which explanations involving my friend's error (rather than my own error) are more reasonable? The fact that I must assess these explanations from within my own perspective means that I'll inevitably assess them by using my own beliefs. But it seems clear that some ways of using my beliefs in arriving at an assessment are not reasonable. I cannot now say, "We have to explain why my friend and I disagree about the probability of rain. The data indicate that it's 55 percent. Since my friend has arrived at 45 percent, it must be she who made the error." So the important question is this: how am I to use my beliefs in assessing the reasonableness of the two explanations in a way that does not just beg the question in favor of the opinion I currently hold?

In seeing how I might be able to do this, let us look back to some more straightforward cases in which it seems clear that disagreement may be discounted substantially without begging the question. Some beliefs-such as high confidence that one is the messiah-are recognized signs of general mental derangement. Other beliefs-such as those involving the sterling qualities of one's children-tend to be held irrationally, even by otherwise rational people. So if my friend disagrees with me by being quite confident that she is the messiah, or that her child is the best violinist in the school, I clearly have some reason to think that the best explanation of our disagreement is that she has made an error. In these cases, it is salient that my reason for favoring the explanation in terms of her error is in an important way independent of my reasoning about the issue on which my friend and I disagree. My beliefs about the relevant general psychological mechanisms do not depend on the question of whether my friend in particular is the messiah or has stunningly exceptional children. This presents a clear contrast with the restaurant or weather-prediction cases, where I seem to lack grounds (independent of my own reasoning on the disputed matter) for favoring the explanation in terms of my friend's error. 
These cases, then, suggest the following (admittedly rough) principles for assessing, and reacting to, explanations for my disagreement with an apparent epistemic peer: (1) I should assess explanations for the disagreement in a way that's independent of my reasoning on the matter under dispute, and (2) to the extent that this sort of assessment provides reason for me to think that the explanation in terms of my own error is as good as that in terms of my friend's error, I should move my belief toward my friend's. ${ }^{15}$ In the next section, I'll examine this account a bit more closely, with an eye toward both making the principles more precise and defending them against plausible objections.

\section{Some Tests and Clarifications}

We might begin by considering an apparent counterexample to this account. Consider an (admittedly unrealistic) variant on the restaurant case, in which my friend becomes confident that our shares of the check are $\$ 450$ - quite a bit over the whole tab. Here, I think that I need not significantly reduce my confidence in my $\$ 43$ answer or raise my very low confidence in the $\$ 450$ answer. ${ }^{16}$ Let us concentrate on our disagreement about whether our shares are $\$ 450$. I think it is initially far from clear that my reasons for selectively suspecting my friend to be in error are truly independent of the reasons on which I base my own belief. If asked why I think my friend is wrong, I'd naturally say something like "Well, $\$ 450$ just can't be right-it's higher than the whole bill!" But this is exactly the reason I'm so confident that $\$ 450$ is false. So the puzzle is: why does it seem right to discount my friend's belief in this Extreme Restaurant Case, but not in the Regular Restaurant Case we looked at earlier?

One answer that suggests itself immediately is that it's simply my initial high level of certainty that my share is not $\$ 450$ which justifies me in discounting my friend's confidence that it is $\$ 450$. But this seems suspect right away, since in the Regular Restaurant Case, I might well have

15. A more formal proposal, very much in the same spirit as (1) and (2), is put forward in Elga forthcoming.

16. Should I change my belief at all? My hedge "significantly" is intended only to acknowledge the (extremely remote) possibility that, for instance, one of my dining companions quietly ordered a bottle of obscenely expensive wine, and I also badly misread the total on the bill. Insofar as my friend's answer of $\$ 450$ would confirm such an (extremely improbable) possibility, some (extremely tiny) adjustment in my beliefs could be in order. 
quite a high initial degree of confidence in my answer-maybe I've been right 99 percent of the time. Yet this seems to give me virtually no reason to favor the explanation in terms of my friend's mistake, given that she has a similar record. And we can also devise cases where I should move my belief considerably toward my friend's, even though I start with a perfectly rational 99.9999 percent confidence that $\mathrm{P}$ is false. Consider a million-ticket lottery in which each ticket is printed with three six-digit numbers that, when added, yield the seven-digit number that is entered into the lottery. My friend has a ticket, and of course I am extremely confident that her ticket did not win. But just to pass the time, I add the numbers in my head and check the result against the winning number printed in the paper. No match, so I remain extremely confident that she hasn't won. But then she adds the figures in her head, checks the result against the paper, and announces that she's won! Here, it seems clear-insofar as I can rationally discount the probability that my friend is just joking, so that this really is a case of disagreement-that I should move my level of confidence in her ticket losing way down below the million-to-one level. So it seems that what determines the correct reaction to finding out about my friend's disagreement is not simply my level of confidence in the proposition about which we disagree.

What, then, differentiates the Lottery Ticket Case from the Extreme Restaurant case? It seems to me that a key to the difference can be seen by focusing, not on the proposition under dispute, but on the reasoning processes on which my opinion and my friend's opinion are based.

Let's first consider the Lottery Ticket Case. Here, my confidence that her ticket didn't win was based both on reasoning from general facts about the lottery and on my mental addition. My friend's very different level of credence is based on that same general reasoning about the lottery and on her mental addition. The explanation for our disagreement clearly lies in the fact that at least one of us made an adding mistake. But even though it was initially rational for me to be extremely confident that her ticket lost, it is not rational for me, after learning of her disagreement, to think that she is more likely to have made an adding mistake than I am. And if her having made an adding mistake is no more likely than my having made one, I cannot maintain my extremely high initial level of confidence that her ticket lost.

Contrast this with the Extreme Restaurant Case, and let us again concentrate on the claim that our shares of the bill are $\$ 450$. Here, as we've seen, the reasoning behind my being so confident in the falsity of 
this claim goes well beyond the calculations by which I arrived at $\$ 43$. My belief is also supported by my reasoning that my share cannot be greater than the whole bill. This is the sort of "commonsense" check that math students in middle school are taught to use to catch arithmetic errors. On the other hand, as the case was set up, I have no reason to suppose that my friend has checked her answer in this way. In fact, I have good reason to doubt that she has. It is much more likely that she calculated and has not brought commonsense checking to bear. Now I take it that this sort of commonsense checking is much less liable to error than mental arithmetic. In fact, if I had come up with $\$ 450$ in my own calculation and then had done the commonsense check, I, like the diligent middle-schooler, would immediately have rejected the calculation. ${ }^{17}$ Thus, given what it's reasonable to believe about the reasoning supporting my friend's and my differing beliefs, it seems that the best explanation of our disagreement here lies in my friend's error. This is why I should not significantly revise my belief.

If this is right, the Extreme Restaurant case does not undermine the principle that in evaluating competing explanations of disagreement about $\mathrm{P}$, my evaluation should be independent of the reasoning that supports my current assessment of $\mathrm{P}$. Although it might be natural for me to say in the Extreme Restaurant Case "Well, my share can't be that high, so she's wrong," that would not really describe why I should favor the explanation in terms of her error. After all, saying that would be parallel to saying “It's $\$ 43$, so she's wrong” in the Regular Restaurant Case. The real ground for thinking that my friend made the error in the Extreme Restaurant Case derives from the fact I have evidence that my assessment of the disputed proposition is supported by an extremely reliable kind of reasoning, but I have no basis for supposing the same about my friend's contrary assessment. ${ }^{18}$ My grounds for discounting my friend's belief are based on considerations about my reasoning, but not on that reasoning itself.

17. Thanks to Adam Wager for pointing out how this observation supports the claim that my trust of my commonsense reasons over my friend's calculation is quite independent of who performed the calculation.

18. We might even consider a third restaurant case, where my friend is a child just learning to do arithmetic. If she gets $\$ 45$, I will quite reasonably think she's the one who's wrong and not adjust my confidence significantly. I might also gloss my reason for thinking her wrong by saying "It's $\$ 43$, so she’s wrong." But my reason for treating our beliefs asymmetrically-for thinking that she's more likely to be wrong than I-derives from my general beliefs about our calculating abilities, not from my particular calculation. 
There may still be some feeling that my reason for favoring the friend's-error explanation in the Extreme Restaurant Case must somehow flow from the brute convincingness of the commonsense considerations-that my talk of an extremely trustworthy kind of reasoning is merely cover for my using the reason for my assessment of $\mathrm{P}$ over again, as a reason for favoring the friend's-error explanation of our disagreement. It is hard to think of a case in which I have this kind of powerful reason for my assessment without having overall reason to favor the friend's-error explanation. In the Extreme Restaurant Case, there seems to be no natural candidate for an equally trustworthy sort of reasoning that my friend could be employing, and it's hard to see how to add one to the case in an intuitively plausible way.

Still, I think we might without too much intuitive absurdity devise a case in which I have the sort of compelling reason I have in the Extreme Restaurant Case, and yet where I don't have reason to favor the explanation in terms of my friend's error. Suppose that I have the sort of calculational abilities associated with "savant syndrome." People with this sort of ability (though usually severely mentally impaired in other ways) have phenomenal abilities to perform calculations very quickly, with amazing accuracy and confidence, in their heads-calculations that ordinary people would find difficult to perform much more slowly with pencil and paper. Some of the people who have this sort of ability are not consciously aware of using any algorithm to solve the problems; they seem to just "see" that the answer is correct. ${ }^{19}$ Suppose that my friend and I both have the ability to determine in this way whether eight-digit numbers are prime. We're both equally extremely accurate, though neither of us is infallible-each of us, very rarely, "sees" things wrong. We're presented with an eight-digit number, and it seems to me that I can just "see" that it's prime. However, my friend disagrees, and after discussing the matter with her, I become convinced that it seems to her that she can just "see" that the number isn't prime. Here, to the extent that I can discount the probability that she's joking, and to the extent that I have evidence that she's not drunk, not especially tired, and so forth, it seems that I should move my belief. After all, I know that I'm fallible on this sort of question and that my friend's record is as good as mine. And this is true even though it still seems to me that I can "see" that my answer is correct. This suggests that even in cases such as the Extreme Restaurant Case, where

19. Oliver Sacks (1985, chap. 23) describes this sort of case. 
one is reasonable in laying the error at one's friend's feet, one's doing this is not rendered reasonable simply by the force of one's own assessment of the disputed claim.

This is not to say, however, that my degree of confidence in my initial opinion is always (or even typically) irrelevant to how I should react to disagreement; in fact, quite the opposite is true. Typically, when I am highly confident in my initial opinion, I have good reason to think that the opinion is based on highly reliable reasoning. But this itself gives me some reason to think that an equally informed person who disagrees with me did not use the same sort of reasoning I did, since it is unlikely that two people, using a highly reliable method of reasoning on the same evidence, would reach different opinions. So in many cases where I know relatively little about the person with whom I disagree, my having a great deal of confidence in my initial opinion should correlate with my giving less credence to the opinion of the other person. But my discounting the opinions of others when I'm highly confident in my initial opinion and know little about the others' reasoning processes does not in the end constitute being partial to my own views just because I confidently hold them. For to the extent that I have evidence that my equally informed friend did in fact use the same sort of reasoning on which my initial opinion was based, I lack reason for favoring my own opinion. These cases, then, do not undermine the impartial principle that I should assess explanations of disagreement in a way that's independent of the reasoning on which my current assessment of the disputed proposition is based.

Let us look briefly at the second principle advanced above-that, to the extent that my assessment provides reason for me to think that the explanation in terms of my own error is as good as that in terms of my friend's error, I should move my belief toward hers. One of the ways in which this principle is underdeveloped is that I haven't specified any mechanism for determining the degree to which I should move my belief in various cases. I cannot attempt that here in any detail. But, to be a bit more specific, I think that the right way to develop a more precise version of the principle would have the following result: when I have excellent reason to think that the explanation in terms of my own error is every bit as good as that in terms of my friend's error, I should come close to "splitting the difference" between my friend's initial belief and my own.

To see why this is reasonable, consider a variant on the doctor case discussed above. Once again, let my initial credences in diagnoses A and $\mathrm{B}$ be 65 percent and 35 percent respectively, and my friend's credences the reverse, and let us both feel equally clearheaded, confident in our 
reasoning, and so on. This time, however, suppose I know from extensive experience that my friend's reasoning tends to be just a little more reliable than my own. On which diagnosis should I base my emergency treatment? I think I should go with B, even though I directly feel the pull of only my own reasoning (if this isn't sufficiently clear, think about what you would want me to do if you were my patient). And the reason I should base my treatment on B is surely because it's now rational for me to have a bit more confidence in B than in A. In other words, if my friend's reliability is just a little bit better than mine, I should more than split the difference with her. But if I should move closer to her initial belief than to mine when she's just a bit more reliable, there seems little reason to deny that I should split the difference evenly when we're fully peers. ${ }^{20}$

Of course, both of the principles discussed above are fairly rough, in various ways. But even without a precise recipe for determining what are the reasons on which I base my belief about $\mathrm{P}$, or for adjudicating goodness of explanations, or for calculating the degree to which I should alter my belief in response to learning of a peer's disagreement, I think it's clear that there are a great many cases in which, intuitively, I may put aside the reasons on which I base my own assessment of $\mathrm{P}$ and see that I have overall reason to think that my friend and I are equally likely to have made the sort of mistake that would explain our disagreement. In such cases, I should revise my belief considerably.

There is, I think, no reason to suppose that taking the required sort of semidetached perspective toward my beliefs should be impossible from the first-person perspective. The first-person perspective is not the dogmatic perspective: it does not entail denying or ignoring the possibility that I have made a cognitive error. The first-person perspective surely poses no barrier to my accepting correction from my friends whom I believe to be smarter, or less biased, or in other ways better at reacting to the evidence. And once this is granted, there seems to be little reason for supposing that it presents some obstacle to my using my epistemic peers as checks on my own thinking. ${ }^{21}$ Fortunately, trapped though I am in my own epistemic perspective, I am perfectly capable of taking an impartial attitude toward some of my own beliefs and using the varied opinions of others as resources for my own epistemic improvement.

20. The question of how to take into account disagreement of other near-peers, and not-so-near-peers, will be discussed below.

21. See Christensen 2000, sec. 5, for related discussion. 
If something along the above lines is right, disagreement matters more than some might seem to think. Van Inwagen $(1996,277)$, discussing those who hold political beliefs contrary to his own, writes:

These people are aware of (at least) all the evidence and arguments that I am aware of, and they are (at least) as good at evaluating evidence and arguments as I. How, then, can I maintain that the evidence and arguments I can adduce in support of my beliefs actually support my beliefs? . . . Well, as with philosophy, I am inclined to think that I must enjoy some sort of incommunicable insight that the others, for all their merits, lack.

Notice that van Inwagen does not claim to be able to point to any reason, independent of the disagreement itself, for thinking that those who disagree with him lack some special insight he has. But if the above reasoning is correct, having some such independent reason is precisely what one would need to maintain rational confidence in the face of disagreement with apparent peers. If my evidence that my (otherwise equally reliable) friend lacks insight on some political issue $\mathrm{P}$ is just that she disagrees with my firmly held belief that P, then I'm in no better position than I am in the weather-forecasting case when I discover that my (otherwise equally reliable) meteorologist friend disagrees with me. The mere fact of disagreement, after all, cannot show that I am the one who "must have" the epistemic edge. If my political or metaphysical or religious disagreements with others resemble the weather-prediction case more than they do the case of the child's musical talent, then insofar as I fail to take my friends' beliefs into account in revising mine, I believe irrationally.

\section{Disagreement and Asymmetries of Justification}

To say that discovery of disagreement does not selectively undermine my friend's epistemic credentials reveals one dimension along which my friend and I occupy symmetrical positions. But that is not to say that all must be symmetrical, even if my friend and I have studied the same evidence equally hard and are in general equally good at reacting to this sort of evidence. After all, it may well be that one of us has, on this occasion, reacted correctly to the evidence and the other one has not.

Kelly presses this point. Suppose that, before we talk, I have, in fact, reacted to the evidence correctly and my friend has not. It seems clear that she should change her opinion. But am I rationally required to do so as well, when I find out that she disagrees with me? Kelly (2005, 180-81) writes: 
On the present view, the rationality of one's believing as one does is not threatened by the fact that there are those who believe otherwise. Rather, any threat to the rationality of one's believing as one does depends on whether those who believe otherwise have good reasons for believing as they do-reasons that one has failed to accurately appreciate in arriving at one's view.

On this view, if I have in fact appreciated the evidence correctly in advance of talking to my friend, it will be perfectly rational for me to maintain my belief, even after learning of my friend's disagreement. ${ }^{22}$

Kelly supports this view by contrasting cases of actual disagreement with cases of merely possible disagreement. He considers different possible worlds in which a student thinks about Newcomb's problem (I've changed a few unimportant details for ease of exposition). In World A, opinion is divided equally between One-Boxers and Two-Boxers. In World B, the evidence and arguments for One-Boxing and Two-Boxing are the same as in World A; nevertheless, it just happens that everyone who thinks about Newcomb's problem in World B is convinced by the arguments for One-Boxing. Kelly asks whether a student who has studied all the arguments in World A should have less confidence in One-Boxing than a similar student in World B. He thinks not-after all, surely the student in World B can realize that in World A, she has epistemic peers who are Two-Boxers. To the extent that she can see that these possible peers would be rational in their support of Two-Boxing, she already has reason to doubt One-Boxing. The lesson, if I understand Kelly correctly, is that it's the arguments that determine what's rational to believe about Newcomb's problem, not contingent sociological facts about what other people think.

However, it seems to me that it cannot generally be that the rationality of my continuing to believe as I do after discovering disagreement is threatened only if those who disagree with me actually have good reasons for their belief that I have failed to appreciate. And I also think that the reason it cannot be true is part of what makes this issue interesting. For I think that Kelly's argument reveals an important tension in the sort of position I want to defend: on my view, I think it has to turn out that

22. A somewhat similar sort of move is made by Plantinga (2000) in defending the legitimacy of maintaining his particular religious views in the face of massive disagreement. Plantinga's position, though, is cashed out in terms of his own externalist account of warrant. Kelly's argument is more general, and I will concentrate on it. Feldman n.d. has a related discussion of the externalist version of this argument. 
even the most rational possible response to the disagreement of peers often embodies a kind of rational imperfection; I will return to this point below.

First, to see why the rationality of my continued belief may be threatened even if there aren't any good reasons for my peer's belief that I failed to appreciate, let us return to the original restaurant case. Suppose one argued as follows: "Granted, both my friend and I sometimes make mistakes when we calculate shares of restaurant bills. But if we've reached different conclusions this time, there may well be an asymmetry between us. Perhaps $\$ 43$ is correct, and she has made the mistake. If that is in fact so, I have no need to revise my belief. The real question is: which figure do the numbers support? And actual disagreement is irrelevant to this question."

Notice that this reasoning would be just as cogent if I were dining with seventeen people, all of whom agreed with the $\$ 45$ figure. It would be just as cogent if all seventeen of those people were expert mental calculators, and I was only an ordinary accurate calculator. But it seems clear that if an acknowledged ordinary accurate calculator learned that seventeen arithmetic whizzes were unanimous in supporting an answer different from his, and yet he maintained undiminished confidence in his answer, he would be exhibiting gross irrationality. And this remains true even if, in this particular case, his answer was actually the correct one.

One more case, not involving anyone else's beliefs, may help make clearer the necessity of taking this sort of rational account of our epistemic fallibilities. Suppose you are a doctor, used to determining appropriate drug dosages for your patients. You are extremely reliable at this, and you quite reasonably do not standardly ask other people to check every time you determine a patient's dosage. Now suppose you've just determined the dosage for one of your patients when you're informed that you've earlier been given a judgment-distorting drug that has been shown through many trials to cause 99 percent of the people who take it to make mistakes in tasks like dosage determination. Let us first ask a moral question: are you morally obligated to get someone else to check your dosage determination before you hand the prescription to the patient? I take it that the answer is obviously "yes." And your moral obligation is in no way contingent on your actually having made a mistake. Since you can't tell whether you've made a mistake, you have no choice but to get the dosage checked. But from where does this moral obligation spring? Clearly, it springs from the fact that you cannot rationally have sufficient confidence in the dosage you determined. Even if it will even- 
tually turn out that you are one of the lucky 1 percent who isn't affected by the judgment-distorting drug, it is not rational for you to maintain your high level of confidence in your dosage determination when you have clear evidence that you may have made a mistake.

The rational requirement to take account of one's epistemic peers' contrary judgments is really just a special case of the more general rational requirement to take into account evidence of one's own possible error. Yet there is undeniably something odd about holding that, in the case where I have managed to arrive at the belief best supported by the original evidence, rationality requires me to abandon it. And this is linked to a structural oddity of rational self-criticism that is worth pausing over. It seems clear that an ideally rational intellect that knew for certain that it was ideally rational would have no reason to defer to the opinions of others who were equally informed, no matter how numerous. So, considered at a certain high level of idealization-"How would an ideally rational intellect think?"-it is attractive to see actual disagreement as a shallow, contingent matter, with no bearing on what it is rational to believe. But I think that this cannot be the right way to think about our present problem. Our problem gets its purchase precisely in our recognition that we're fallible thinkers. Our problem is how to deal (rationally) with the fact that we're liable to fall short of ideal rationality. In a way, we're asking "What's the ideally rational response to evidence that I'm not ideally rational?"

This is why it makes a difference whether my friend actually does disagree with me, or whether I just know she could have disagreed with me. The fact that disagreement by epistemic peers is possible is a constant and inevitable consequence of our being nonideal thinkers. So the mere possibility of disagreement by peers tells us only what we already know. Actual disagreement with peers is informative because it provides evidence that a certain possibility - the possibility of our having made an epistemic error-has been actualized. It makes what we already know possible more probable. ${ }^{23}$ Could we get this same sort of evidence simply by asking ourselves whether merely possible peers might disagree with us rationally? It seems not-for in those cases where we have made a mistake in assessing the evidence about $\mathrm{P}$, we are overwhelmingly likely to make

23. A related point is made by Todd Stewart (n.d.) in reply to an argument in Alston 1991. (Alston claims that merely possible competing epistemic practices would pose as great a threat to our practice as would actual competing practices; thus if we aren't worried by merely possible competitors, actual competitors should not worry us either.) 
the same mistake in assessing how a rational peer would assess the same evidence about the same proposition.

For this reason, it seems to me that, when we compare the two students of Newcomb's problem, they should (given the sorts of assumptions we've been making about other cases, at least) have different levels of confidence in One-Boxing. If each of them reasonably sees herself as being among others who (opinions on Newcomb's problem aside) are her epistemic peers, then the denizen of the divided World A should be less confident of the truth of One-Boxing than the denizen of World B, where all the other smart and knowledgeable people take the evidence and arguments to support One-Boxing. The One-Boxing denizen of World A has real evidence that she may have made some mistake in evaluating the arguments.

Now I want to emphasize that this is not to argue that in cases like the weather-prediction case, my friend and I are in entirely symmetrical epistemic situations after we talk. If I originally got it right and she originally got it wrong, then if she doesn't change her belief at all, she's made two epistemic mistakes. First, she evaluated the "purely meteorological" evidence wrong. Second, she ignored evidence-provided by her conversation with me-that she'd made a mistake. I avoided making the first mistake, but joined her in making the second: I ignored evidence indicating that I had made a mistake.

Perhaps there is some temptation to think that I didn't make any mistake in ignoring her opinion since, as it turned out, I ended up with the opinion that was best supported by the evidence. But I think that this cannot be quite right. My opinion is the one that is best supported by the evidence I had before talking to my friend. But my friend's belief is additional evidence, which bears on the probability that I made a mistake in my initial judgment-and, hence, bears on the probability of rain.

More generally: if one is to take seriously the possibility that one has made an epistemic mistake, one must be prepared to change one's beliefs in response to evidence that one has made a mistake. ${ }^{24}$ Now this evidence of mistake-like almost all evidence about anything-can be misleading. So if one lets one's beliefs be guided by this evidence, one will sometimes be led to worsen one's beliefs. But there is nothing paradoxical about this. Rationality requires conforming one's belief to the

24. Strictly speaking, this may not always be true in cases where the evidence fails to indicate the direction of one's mistake. 
evidence-even though the evidence sometimes turns out in the end to have been misleading.

However, the sort of evidence provided by the opinions of peers differs from other kinds of evidence in an interesting way, one that reflects from a somewhat different angle the oddity of rational self-criticism-especially on certain conceptions of rationality. Consider the "misleading evidence" case where I've correctly reacted to evidence E by forming opinion $\mathrm{O}$, and find out that my friend has reacted differently, forming opinion $\mathrm{O}^{\prime}$ on the basis of E. My friend's opinion is misleading evidence because it suggests that E supports $O$ ' rather than $O$. But the question of whether $\mathrm{E}$ supports $\mathrm{O}$ or $\mathrm{O}$ ' is a kind of question to which evidence is often thought not to be relevant-the basic confirmation relations are often taken to be a priori. On this understanding, my friend is providing me with evidence against an a priori truth. This is related, of course, to the point that an ideal intellect which was rationally certain of its perfection would not be bothered by such evidence. ${ }^{25}$

Unfortunately, we are not ideal intellects. And the fact that we're epistemically imperfect is manifested in part by our inability to tell, just by introspection or hard thinking, whether we've made a mistake. So even when we in fact haven't made a mistake, we would be irrational simply to dismiss the possibility of error. Fortunately, other people's opinions serve, alongside our own introspection and hard thinking, as evidence about whether we've made a mistake. When this sort of evidence indicates that we have made a mistake, rationality requires taking account of this evidence.

\section{Relaxing the Conditions}

Our discussion of the restaurant, weather-prediction, and Newcomb cases has been circumscribed by some significant assumptions or stipulations. First, we assumed "Rational Uniqueness," the view that there is a unique maximally epistemically rational response to any given evidential situation. Then we made two stipulations about the particular

25. The point in the text is also related to the point that the mere possibility of epistemic imperfection can, once recognized, entail actual epistemic imperfection-at least as this is often conceived. Suppose one proves a theorem in logic, yet realizes that it is possible that one has made a mistake in the proof. Insofar as one acknowledges a nonzero probability that one has made an error, one should have less than full confidence in the theorem-even though logical omniscience is often taken (I think correctly) as a rational ideal. I discuss this issue at length in Christensen forthcoming. 
cases under discussion: that I had good reason to suppose my friend to have considered all the same evidence I had considered (let's call that "Evidential Equality") and that I had good reason to think her and myself to be equally good at responding to that kind of evidence (let's call that "Cognitive Parity"). But the assumption of Rational Uniqueness can certainly be challenged, and the stipulations of Evidential Equality and Cognitive Parity, while not unrealistic in any troublesome way (they don't include bizarre science fiction), do limit the discussion to some fairly atypical cases. In this section, then, I'd like to see how the lessons of these circumscribed discussions might apply when the conditions are relaxed.

Let us turn first to Rational Uniqueness. Suppose that, in many situations, rationality is somewhat permissive-that there is more than one maximally rational response to a given evidential situation. It might seem that, once this was allowed, the case for changing my opinion in the direction of my friend's opinion would evaporate. After all, the whole point of the live-and-let-live attitude is that my friend and I might both be maximally rational in our responses to the evidence even if our degrees of confidence in the relevant proposition differ.

But the case for belief change does not evaporate so readily. Consider another variant on the medical case, in which we suppose that there really is a range of maximally rational ways of weighing simplicity and fit with the data. When I find out that my colleague disagrees with me, then, I cannot conclude from that fact alone that one of us must be reasoning suboptimally. But does that mean I can safely ignore her assessment? No. For one thing, if our opinions are far enough apart, it may still be that not both of them can be rationally optimal (after all, not just any weighing of simplicity and fit need be maximally rational). Second, if my opinion and my colleague's opinion are far enough apart so that if they both were maximally rational, they'd be at opposite ends of the spectrum of maximally rational opinion, then the extent of our disagreement would provide some evidence that at least one of our opinions was rationally suboptimal. So, although I find the Rational Uniqueness assumption quite attractive, it is certainly not necessary in order for known disagreement to provide reason for change of belief.

Let us turn next to relaxing the stipulation of Evidential Equality. First, it is worth noting that what might be called Evidential Parity would seem to produce the same results as Evidential Equality. Suppose I have good reason to believe that my friend's evidence, though different from mine, is just as good (for example, suppose my friend and I have done 
similar polls of distinct but comparable sample populations and have reached conflicting conclusions). Here, the reasons for our disagreement need not be cognitive-it could just be that one of the samples was not representative. But absent some special reason for treating her evidence or reasoning differently from mine, it seems clear that in evaluating explanations for our disagreement, I should regard our opinions as equally likely to be accurate, and thus I should alter my opinion toward hers. ${ }^{26}$

In fact, even evidential parity is not needed in order for disagreement to provide substantial reasons for belief revision. Suppose that in the polling case, my friend's sample was a little bit smaller. Here, I have some reason to favor my assessment, but it is clear that I don't have reason to discount her assessment severely. Consequently, I should alter my belief substantially toward hers. So although the evidential value of my friend's belief is highest when she has more evidence than I do and considerable when she has evidence equal to mine, it's still useful when she has less evidence.

Finally, often one won't have much of a specific idea how well informed other people are. Still, this does not eliminate the evidential value of their beliefs. Pace Foley, I should take the beliefs of others into account in many such cases, for in many cases, where I'm not at the wellinformed end of the general spectrum of people, it is only reasonable for me to expect that a fairly random person has a level of evidence which makes her opinion a valuable epistemic resource. It seems that the lessons of the pure evidential equality cases generalize quite widely.

What about Cognitive Parity? Here, it seems to me that many of the points that applied to Evidential Parity can be duplicated. If I take seriously the possibility that I could have figured my restaurant tab incorrectly, then even if my friend is a competent, but slightly less accurate, calculator, her disagreement should cause me to reduce my confidence in my answer. And if I don't know much about my friend's cognitive abilities, then unless I think myself much less likely than the average person to make mistakes on the topic in question, her disagreement should count substantially.

In sum, then, it turns out that the lessons of the artificially pure cases apply to a great many ordinary situations. In general, unless one has reason to consider oneself to be in a highly privileged epistemic posi-

26. This is an example instance of Feldman's principle that "evidence of evidence is evidence." 
tion-both with respect to the evidence and with respect to one's ability to respond correctly to that evidence-the disagreement of others will provide good reason to revise one's beliefs.

It's worth pointing out, however, that with respect to many of my beliefs, I do have good reason to think that I'm in an especially good epistemic position. For some beliefs, I have more evidence than the average person, and for others, I've thought more carefully than the average person. Moreover, even when it comes to people I know, I'll often have reason to trust my own reasoning more than theirs. It's often hard to tell, for example, how hard another person has thought about a given matter, or whether they're tired or distracted; whereas I might know that I've studied a matter carefully and know that I feel alert. So although the epistemic importance of disagreement extends far beyond cases of disagreement by epistemic peers, I will often have solid, perfectly impartial reasons for thinking that particular disagreements are more likely to be explained in a way that favors my belief's accuracy. In fact, the prevalence of this sort of situation may well help explain the intuitive appeal of the view that I've been arguing against-that one may generally privilege one's own beliefs in adjudicating disagreements with others. ${ }^{27}$

\section{Qualitative Belief and the Threat of Skepticism}

I've been discussing belief in quantitative terms and arguing that disagreement should often occasion change of degree of confidence. But some who have discussed this issue have cast it in terms of a qualitative, all-or-nothing notion of belief. And one of the issues seems to be: when does disagreement provide reason for suspending belief? Does the sort of approach I've been defending lead to some unacceptable level of skepticism?

There is no clear, uncontroversial way of seeing the relation between graded and all-or-nothing belief. But I take it that on any reasonable way of looking at the matter, evidence that can mandate significant changes in rational degree of belief will often mandate changes in rational all-or-nothing belief. ${ }^{28}$ So there should certainly be many cases

27. This last suggestion is due to Arthur Kuflik.

28. I don't mean to assume here that there's some fixed threshold of graded belief that correlates with all-or-nothing belief (such an assumption contradicts what many are inclined to say about lottery cases). But it should be uncontroversial that the all-ornothing attitude that it is rational to take toward $\mathrm{P}$ in typical situations is sensitive to evidence which affects the degree of confidence it is rational to have in $\mathrm{P}$. 
where the discovery of disagreement by peers mandates suspension of belief_-or even disbelief_-in a proposition that was initially believed rationally. The Ordinary Restaurant case is, to my mind, a nice example in which suspension is mandated; add a few more peers who get $\$ 45$, and disbelief in $\$ 43$ is rationally required.

Does the disagreement of an epistemic peer always mandate withholding (supposing just a two-person case)? I think probably not. ${ }^{29}$ Suppose that my friend has a degree of confidence barely sufficient (given the context) for rational belief that not-P, but that I have a degree of confidence much greater than that required for believing P. It might be that even if I split the difference in degree of confidence with my friend, I'll still have enough confidence in $\mathrm{P}$ for all-or-nothing belief. In some such cases, it will be rational for me to maintain my (all-or-nothing) belief. Nevertheless, it seems to me that disagreement in all-or-nothing belief should often lead to suspension of belief by both sides.

Is this a bad thing? I've been casting disagreement in a deliberately positive light—as reflecting opportunities for epistemic improvement. But I can understand how this sort of rhetoric might arouse suspicion-as does the rhetoric of those university administrators who have resolutely purged "crisis" and even "problem" from their vocabularies, in favor of "challenge" and "exciting opportunity for change." And others who have thought about this problem have clearly worried about the threat of skepticism. So I want to say a word or two in defense of my happy-face attitude.

I think it's important to notice that disagreement is not evenly distributed. There are great bodies of belief in mathematics, in the sciences, and in our everyday conception of the world that are not subject to significant peer-to-peer disagreement. On the other hand, there are areas of morality, religion, politics, and economics, and, unfortunately, philosophy which are rife with disagreement. Why is this? It seems clear that disagreement flourishes when evidence is meager or poorly distributed, or when, due to our emotional or intellectual limitations, we are just not very good at reacting correctly to the evidence. In other words, disagreement flourishes when epistemic conditions are bad. To focus in on my own field, I think that we all should acknowledge that epistemic conditions are not so great in philosophy.

29. Here, I think I side with Kelly and not with the letter of what Feldman says (though I think that even here, what I say is very much in the spirit of Feldman's position). 
The worry, then, is that in fields like philosophy, taking account of disagreement in the ways I've been defending would lead to general withholding of belief in many cases. In degree-of-belief terms, the worry is that disagreement would often resolve away from the ends of the credence scale. I think that this is true. In philosophy, at least, I think that the parties to disputes are fairly often epistemic peers. And often, if one of the parties were to consider the question of what explained his disagreement with a peer, and if he evaluated explanations in a way didn't rely on the reasoning underlying his own disputed position, he would find that he had good reason for taking the explanation in terms of his own error to be just as good as the explanation in terms of his peer's error. In such a case, he should not hold his position with the sort of confidence that philosophers often seem to have about so many controversial issues. ${ }^{30}$

In general, I think it's true that if those who work in poor epistemic conditions were more epistemically rational, there would be less disagreement, and many positions would be held with less confidence. ${ }^{31}$ This would, of course, have some unwelcome consequences, even beyond the frustration of acknowledging that we often cannot confidently answer the questions we study. I think there would even be a possible epistemic downside to this sort of result. It's quite plausible that knowledge is best advanced by people exploring, and attempting to defend, a variety of answers to a given question. ${ }^{32}$ Perhaps, human psychology makes this easier to do when investigators actually have a lot of confidence in the hypotheses they're trying to defend. Certain sorts of inquiry might well work best when a variety of investigators have irrationally high levels of confidence in a variety of pet hypotheses. So there may well be important epistemic benefits to certain patterns of irrational belief. But I would argue that the patterns of belief are no more epistemically rational for all that. ${ }^{33}$

30. Thus, suppose I find, for example, that half of my philosophical peers who carefully read this essay remain quite unconvinced of its conclusions, and suppose that, independent of the reasoning in this essay, explaining this disagreement in terms of my missing something is as plausible as explaining the disagreement in terms of their missing something. If that happens, it would be less than fully rational for me to remain as confident of these conclusions as I currently am.

31. For views that attempt to limit this effect, see Pettit 2006 and Elga forthcoming.

32. See Kitcher 1993, chap. 8. Thanks to Mark Moyer for pressing this point.

33. Consider the claim that those with unrealistically high self-assessments are more successful (see Taylor 1989 for evidence supporting this claim). General success in life may well lead to epistemic success in endeavors such as science. But that wouldn't render the unrealistic self-assessments epistemically rational. See Christensen 2004, 173ff. for more on this. 
It seems obvious to me that in philosophy-and in certain other disciplines as well-even the best practitioners make mistakes pretty frequently. And if one is part of a discipline whose methods are so clearly vulnerable to error, should one not take this as powerful reason for using precautions against unfounded confidence? It seems to me that such precautions, when available, are a good thing. The fact of disagreement is old, but bad, news; it is bad because it indicates the relatively benighted conditions under which we work. But adjusting our beliefs in the direction of those peers with whom we disagree should be welcomed as a valuable strategy for coping with our known infirmities. After all, I want my own beliefs to be those best supported by the evidence. So if the beliefs of other decent, yet imperfect, inquirers turn out to serve as partial checks against my falling short of this goal, that strikes me as being pretty good news.

\section{References}

Alston, William P. 1991. Perceiving God. Ithaca, NY: Cornell University Press. Christensen, David. 2000. "Diachronic Coherence vs. Epistemic Impartiality." Philosophical Review 109: 349-71.

- 2004. Putting Logic in Its Place: Formal Constraints on Rational Belief. New York: Oxford University Press.

—. Forthcoming. "Does Murphy's Law Apply in Epistemology? Self-Doubt and Rational Ideals." Oxford Studies in Epistemology 2. Oxford: Oxford University Press.

Elga, Adam. 2005. "On Overrating Oneself . . . and Knowing It. Philosophical Studies 123: 115-24.

—. Forthcoming. "Reflection and Disagreement." Nô̂s.

Feldman, Richard. Forthcoming. "Reasonable Religious Disagreements." In Philosophers without Gods: Meditations on Atheism and the Secular Life, ed. Louise Antony. New York: Oxford University Press.

—. n.d. "Reasonable Disagreements." Unpublished manuscript.

Foley, Richard. 2001. Intellectual Trust in Oneself and Others. New York: Cambridge University Press.

Kaplan, Mark. 1996. Decision Theory as Philosophy. New York: Cambridge University Press.

Kelly, Thomas. 2005. "The Epistemic Significance of Disagreement." Oxford Studies in Epistemology 1: 167-96.

Kitcher, Phillip. 1993. The Advancement of Science: Science without Legend, Objectivity without Illusions. Oxford: Oxford University Press.

Pettit, Philip. 2006. "When to Defer to Majority Testimony—and When Not." Analysis 66: 179-87. 
Plantinga, Alvin. 2000. Warranted Christian Belief. New York: Oxford University Press.

Rosen, Gideon. 2001. "Nominalism, Naturalism, Epistemic Relativism.” Philosophical Perspectives 15: 69-91.

Sacks, Oliver. 1985. The Man Who Mistook His Wife for a Hat. New York: Summit Books.

Stewart, Todd. n.d. "The Competing Practices Argument and Self-Defeat." Unpublished manuscript.

Taylor, Shelley. E. 1989. Positive Illusions: Creative Self-Deception and the Healthy Mind. New York: Basic Books.

Trakakis, Nick. n.d. "Is Disagreement Epistemically Insignificant? A Reply to Kelly." Unpublished manuscript.

Van Inwagen, Peter. 1996 [1999]. "It is Wrong, Everywhere, Always, and for Anyone, to Believe Anything upon Insufficient Evidence." In Philosophy of Religion: The Big Questions, ed. Eleonore Stump and Michael J. Murray. New York: Blackwell.

White, Roger. 2005. "Epistemic Permissiveness." Philosophical Perspectives 19: 445-59. 
